\title{
PRINCÍPIO DO PROTETOR-BENEFICIÁRIO: POR UMA JUSTIFICATIVA DE EFETIVAÇÃO À LUZ DA ANÁLISE COMPORTAMENTAL DO LEGISLADO
}

\author{
PROTECTOR RECEIVER PRINCIPLE: FOR A JUSTIFICATION OF \\ ARCHIEVEMENT IN THE LIGHT OF THE LEGISLATED BEHAVIORAL \\ ANALYSIS
}

${ }^{1}$ Raissa Pimentel Silva

\section{RESUMO}

O presente ensaio foi concebido com o escopo de justificar a necessidade de aprimoramento e efetiva operacionalização das normas diretamente conexas à função promocional do Direito Ambiental, em especial o novel princípio do Protetor-Beneficiário, a partir da compreensão de que o clássico modelo normativo de comando e controle não vem se revelando suficiente à consecução do almejado direcionamento comportamental dos legislados, especialmente ao se considerar um cenário em que as fragilidades que permeiam o exercício do poder de polícia estatal, em especial os atos de fiscalização, são latentes. Para instaurar a exposição, serão apresentados, a partir de uma análise econômico-comportamental, os estereótipos sociais sustentados por Oliver Wendel Holmes, na obra The Path of the Law, consignando a caracterização dos perfis do good man e do bad man, este último considerado por Jack Balkin uma versão especial do homo economicus, interessado em maximizar as suas satisfações pessoais. Assentada a premissa de que os indivíduos, em geral, adotam ações voltadas à consecução de um auto-interesse, passar-se-á, em segundo momento, à análise da missão e funções atribuídas às normas jurídicas. Para afirmar que o Direito exerce o papel primordial de regulação dos comportamentos sociais e, para tanto, deve valer-se, de modo harmônico, de instrumentos negativo-repressórios e positivo incentivatórios, serão adotadas como pilares as lições de Norberto Bobbio, extraídas de suas obras Teoria geral do Direito e Da estrutura à função: novos estudos da teoria do direito. Por fỉm, à guisa de ilustrar a lógica que permeia o princípio do protetor-beneficiário, será apresentada a Lei Estadual no 13.223/2015, que institui a Política Estadual de Pagamentos por Serviços Ambientais do Estado da Bahia.

Palavras-chave: Princípio do protetor-beneficiário, Protetor-recebedor, Pagamento por serviços ambientais, Função promocional do direito ambiental, Comportamento autointeressado, Lei estadual $n^{\circ} 13.223 / 2015$ bahia

\footnotetext{
${ }^{1}$ Doutoranda em Direito pela Universidade Federal da Bahia - UFBA, Bahia (Brasil). Professora de Direito Ambiental pela Universidade Federal da Bahia - UFBA, Bahia (Brasil). E-mail: raissa.pimentel@ sema.ba.gov.br
} 


\section{ABSTRACT}

This trial was designed with the aim of justifying the need for improvement and effective implementation of standards directly related to the promotional role of environmental law, especially the new principle of the protector-receiver, based on the understanding that the classic normative model of command and control does not come out to be enough to achieve the desired behavioral targeting of legislated, especially when considering a scenario where the weaknesses that underlie the exercise of power of the state police, especially the acts of enforcement, are latent. To set up the explanation, will be presented, from an economic and behavioral analysis, the social stereotypes sustained by Oliver Wendell Holmes in the work The Path of the Law, consigning the characterization of the good man and bad man profiles, the latter considered by Jack Balkin a special version of homo economicus, interested in maximizing their personal satisfactions. Seated the premise that individuals, in general, adopts actions aimed at achieving a self-interest, will be presented, on the second part, the analysis of the mission and functions of the legal rules. To say that the law plays the primary role of regulation of social behavior and, therefore, should consider, harmonic mode, negative-repressive instruments and positive encourager ones, will be adopted, as pillars, lessons of Norberto Bobbio, drawn from his work General Theory of Law and From the function structure: further study of legal theory. Finally, by way of illustrating the reason behind the principle of protector - receiver, State Law No. 13.223 / 2015 establishing the State Policy on Payments by the State of Bahia Environmental Services will be presented.

Keywords: Protector - receiver principle, Payment for environmental services, Promotional function of environmental law, Self- interested behavior, State law 13.223/2015 bahia, brazil

"Prohibition is easy to legislate (though not necessarily to enforce); but how do we legislate temperance? ${ }^{1,}$

- Hardin, Garrett. 


\section{INTRODUÇÃO}

A edição de normas tendentes à eficácia - esta compreendida como êxito no direcionamento comportamental do legislado - é, certamente, um dos maiores desafios do Poder Público na atualidade. No desempenho desta complexa tarefa, o diagnóstico dos os anseios, valores e interesses econômicos dos diversos atores sociais torna-se ferramenta de manejo indispensável. Somente a par dos interesses que propulsionam a conduta dos indivíduos podem ser adotadas pelos agentes normatizadores estratégias aptas a induzir a ação do comandado em direção ao comportamento socialmente desejado.

Lançadas estas considerações preliminares, pode-se adentrar ao estudo dos argumentos que permitem sustentar a tese suscitada no título deste ensaio. Para melhor compreensão do leitor, os temas que compõem os substratos do presente escrito encontram-se organizados em quatro tópicos distintos.

No primeiro, serão apresentadas as idéias centrais de Oliver Wendel Holmes, consubstanciadas na obra The Path of the Law, consignando a caracterização dos perfis comportamentais do good man e do bad man. Será apresentado, tangencialmente, um paralelo entre as idéias de Holmes e o juízo de John Rawls acerca de pessoas razoáveis e pessoas irrazoáveis, bem como pinceladas as bases do movimento que pode ser compreendido como Economical Analysis of the Law (como ponto de partida para a explanação que se pretende aqui empreender, adota-se, como premissa, a concepção de que todas as ações humanas são motivadas por análises valorativas com vistas à satisfação de um auto-interesse. A idéia será melhor elucidadaao longo do escrito).

No segundo, far-se-á análise acerca da natureza e função do Direito, destacando, de início, o papel diretivo das normas jurídicas - a partir da compreensão de que o Direito,

\footnotetext{
${ }^{1}$ Tradução livre da autora: "Legislar proibição é fácil (embora não necessariamente fazer cumpri-la); Mas como nós legislamos temperança?"
} 
enquanto conjunto ordenado de imperativos hipotéticos, viabiliza o exercício do livreabítrio por parte do legislado, que decide agir em acordo (ou em desacordo) com o mandamento legal com vistas à consecução de um determinado resultado previamente conhecido(de modo que o diálogo entre norma e legislado pode ser traduzido através da expressão "se....então"). Adotando-se a premissa de que as normas jurídicas estatuem comandos não bastantes em si mesmos (carecendo da opção de ação por parte do legislado), passar-se-á à exposição daquilo que é compreendido por Norberto Bobbio como a função promocional do Direito, ou seja, a necessidade de introdução de estímulos, sejam positivos - a partir da adoção de sanções premiais e/ou facilitações - ou negativos, a partir da adoção de sanções repressivas - passíveis de interferir efetivamente no direcionamento da conduta do legislado.

Em seguida, far-se-á uma análise crítica do modelo normativo predominantemente escolhido pelo legislador brasileiro em se tratando de normas de tutela ambiental, buscando demonstrar o porquê da ineficiência (e insuficiência) de muitas das normas de caráter repressivo-negativas: i. sustentar-se-á que o típico bad man brasileiro, ciente das fragilidades estatais no que concerne à fiscalização ambiental, bem como da possibilidade iminente de impunidade, certamente optará pela infração, após sopesamento de riscos e vantagens advindas do descumprimento legal; ii. Do good man brasileiro, noutra senda, imerso em cultura antropocêntrica característica das sociedades ocidentais, não se pode esperar mais que a ação em estrita adstrição aos parâmetros legais, porquanto não atribua ao meio ambiente valor inerente e posição de relevante considerabilidade moral (ou seja, não engendrará ações positivas em favor do meio ambiente que extrapolem os parâmetros legalmente exigidos).

Por fim, para concluir que o Direito, no exercício da regulação dos comportamentos sociais deve valer-se, de modo harmônico, de instrumentos negativo-repressórios e positivo-incentivatórios, será demonstrada a necessidade de enfrentamento do comportamento do bad man e do good man holmesianos como alerta para a necessidade de uma efetiva consecução das diretrizes insculpidas no princípio ambiental do ProtetorBeneficiário. Nesta trilha, a par da exposição dos mandamentos de otimização contidos no princípio ambiental em comento, será apresentada a Lei Estadual nº 13.223/2015, que institui a Política Estadual de Pagamentos por Serviços Ambientais do Estado da Bahia, 
tecendo considerações preambulares acerca do diploma legal (cumpre deixar assentado, de plano, que o presente ensaio não objetiva abordar, com riqueza de detalhes, os modos e mecanismos de operacionalização das estratégias de sancionamento premial possíveis, mas apenas apresentar as premissas que permitirão inferir a real necessidade de uma efetiva incorporação ao ordenamento jurídico pátrio do princípio do protetor-beneficiário).

\section{COMPORTAMENTO AUTO-INTERESSADO DO LEGISLADO - O GOOD MAN E O BAD MAN HOLMESIANOS}

Oliver Wendell Holmes Jr., em The Path of the Law, introduz os conceitos de good man e bad man, para em seguida,afirmar que a adequada compreensão do Direito deve ser obtida a partir da adoção da perspectiva daquele indivíduo considerado um bad man. $\mathrm{O}$ ponto central da distinção entre o bad man e o good man reside no grau de aproximação ou dissociação entre razões para direcionamento da conduta, temor normativo e valores morais. Explica o juiz norte-americano:

You can see very plainly that a bad man has as much reason as a good one for wishing to avoid an encounter with the public force, and therefore you can see the practical importance of the distinction between morality and law. A man who cares nothing for an ethical rule which is believed and practised by his neighbors is likely nevertheless to care a good deal to avoid being made to pay money, and will want to keep out of jail if he can. ${ }^{2}$ (HOLMES, 2008, p. 03).

O conceito de bad man, ao contrário do que se pode defluir a partir de uma tradução precipitada da expressão, não se vincula estritamente àquele indivíduo perverso ou de má índole, mas àquele que aparenta desapego às regras morais, direcionando sua conduta de modo a evitar as conseqüências legais e sanções positivadas, visando apenas a sua própria

\footnotetext{
${ }^{2}$ Tradução livre da autora: "Pode-se ver de forma clara que um homem mau tem tanta razão quanto um homem bom para desejar evitar um encontro com o poder-público, sendo possível notar a importância prática da distinção entre moralidade e lei. Um homem que não se importa com uma regra ética criada e posta em prática por seus vizinhos tende a preocupar-se, no entanto, em evitar ser compelido a pagar alguma quantia em dinheiro, e deseja manter-se fora da prisão, se puder".
} 
satisfação; O good man, por oposição conceitual, é aquele age em respeito, sobretudo, às regras da sua consciência e às normas éticas e de conduta moral que regulam o convívio social. Talvez a distinção possa ser mais bem aclarada a partir da simples percepção dos distintos comportamentos possíveis diante de uma mesma situação: o adimplemento voluntário de dívida prescrita. Enquanto um good man esforçar-se-ia para saldar o débito e honrar a obrigação assumida, ainda que não mais exigível perante os ditames legais, por acreditar ser ética e moralmente correto, umbad man provavelmente não iria saldar o débito, seguro de que os braços do Estado não mais lhe alcançam (poderia, não obstante, cuidar de quitar a dívida se assim lhe for conveniente e por motivos egoísticos, a exemplo da possibilidade de restabelecimento de crédito ainda mais vantajoso perante o credor).

Perfeita, nesse sentido, a leitura de Jack Balkin, professor de Direito Constitucional da Universidade de Yale, quando afirma ser o bad manholmesiano uma versão ideal do típico homo economicus, afastado da noção de obrigação moral e interessado apenas em maximizar suas vantagens pessoais, alheio às necessidades de terceiros, exceto quando estas sirvam como obstáculo à consecução de interesses egoísticos (BALKIN, 1998, p. 03).

Percebe-se a influência de tal perspectiva pragmatistaentre os entusiastas da Economical Analysis of $\mathrm{Law}^{3}$, em especial o jurista norte-americano Richard Posner, que realizou indiretamente releitura da metáfora do bad man holmesiano a partir do pressuposto basilar da análise econômica do direito - qual seja a idéia de que todas as pessoas, à exceção apenas das crianças em tenra idade e portadores de distúrbios mentais, são maximizadoras racionais de suas satisfações ${ }^{4}$, afirmando que os indivíduos agem não em atenção às prescrições estatais positivadas, mas porque assim lhes é conveniente. Assim, desde as decisões mais corriqueiras, como a de um motorista que decide se ultrapassará sinal vermelho ou uma parte que pondera se irá ou não cumprir cláusula de um contrato que celebrou, àquelas aparentemente mais impactantes, à exemplo do indivíduo que decide se

\footnotetext{
${ }^{3}$ A disciplina foi importada para o Brasil sob a denominação de Análise Econômica do Direito. Para aprofundamento, sugere-se a leitura da obra Metodologia e Epistemologia da Análise Econômica do Direito, magistério de Ivo Gico Jr.

${ }^{4}$ Cumpre registrar que, segundo Posner, "Deve ficar subentendido que tanto as satisfações não-monetárias quanto as monetárias entram no cálculo individual de maximização (de fato, para a maioria das pessoas, o dinheiro é um meio, e não um fim) e que as decisões, para serem racionais, não precisam ser bem pensadas no nível consciente [...]” (2007, p. 473)
} 
irá ou não praticar um crime, busca-se a sempre a máxima satisfação dos interesses pessoais. Trocando verbetes, um indivíduo pode conscientemente violar uma norma ou descumprir um contrato se, após ponderação dos benefícios e consequiências do ato, entender ser vantajoso agir contra legem.Isto, pois, a decisão de obedecer a norma deriva não da norma em si, porquanto legislada e imposta em abstrato, mas das consequências (leia-se: ponderação entre vantagens e desvantagens do adimplemento) possíveispelo ato de desobedecê-la (POSNER, 2007, p. 473,474).

Apesar de louváveis os argumentos otimistas lançados à guiza de criticar tal abordagem pragmático-economicista - à, exemplo, destaque-se o posicionamento categórico de Amartya Sen (2014, p. 63) ao refutar a idéia de que uma escolha racional consiste apenas na promoção de um interesse particular: "Há uma considerável resistência à idéia de que deve ser patentemente irracional - e estúpido - alguém tentar fazer alguma coisa para os outros, exceto na medida em que fazer o bem reforce seu próprio bem-estar" negar, fundamentadamente, a idéia do comportamento auto-interessado não é tarefa simples, podendo soar ingênuo.

Pertinente consignar a ressalva no sentido de que se está aqui a defender e/ou justificar a manuntenção de um comportamento egoísta. Perfeito seria se somente existissem indivíduos com o perfil do good man holmesiano, ouque agissem sempre em acordo com a posição original de igualdade primordial de John Rawls em que, uma vez estabelecida uma concepção política de justiça aceita socialmente, através de um contrato social hipotético, esta seria suficientemente apta a influenciar o comportamento dos indivíduos daquela sociedade, que abdicariam dos seus interesses particulares em prol do adequado funcionamento da sociedade.

Cumpre aqui tecer um breve parêntesis para demonstrar uma aproximação entre as noção de bad man e good man, de Holmes, e o juízo de Rawls acerca das pessoas razoáveis e pessoas irrazoáveis. Rawls parece admitir a incompletude da sua teoria da equidade como posição original de igualdade na escolha dos princípios que devem nortear o ordenamento jurídico, ao aceitar a existência de pessoas irrazoáveis, a saber:

Reasonable persons, we say, are not moved by the general good as such but desire for its own sake a social world in which they, as free and equal, can cooperate with others on terms all can accept. They insist that 
reciprocity should hold within that world so that each benefits along with others. By contrast, people are unreasonable in the same basic aspect when they plan to engage in cooperative schemes but are unwilling to honor, or even to propose, except as a necessary public pretense, any general principles or standards for specifying fair terms of cooperation. They are ready to violate such terms as suits their interests when circumstances allow (2005, p. 112). ${ }^{5}$

Retomando à linha de argumentação, o que se sustenta, não obstante, é que a crença otimista no sentido da possibilidade de uma reforma comportamental através, apenas, da conscientização popular acerca dos malefícios sociais das ações individualmente praticadas em desacordo com as normas - jurídicas, morais e sociais -soa um tanto utópico, principalmente considerando o perfil do homem médio ocidental ${ }^{6}$, afastado da noção de que o meio ambiente possui um valor inerente (tema este que será melhor detalhado no tópico seguinte).Defende-se aqui, portanto, não somente a plausibilidade da abordagem do comportamento auto-interessado, mas também a importância de tal análise comportamental com vistas à adoção, pelo poder público, de estratégias eficazes voltadas ao direcionamento do da conduta do legislado à adoção das ações socialmente desejadas.

Destarte, de acordo com a perspectiva holmesiana, o legislador (ou juiz consuetudinário, em se tratando de ordenamentos instituídos no modelo da common law), deve ter em vista os padrões de conduta e motivações comportamentais típicos do bad manquando da elaboração e aplicação da norma. Somente a par dos interesses propulsores das condutas dos legislados - e, para tanto, o bad man seria o parâmetro perfeito, posto que

\footnotetext{
${ }^{5}$ Tradução livre da autora:Pessoas razoáveis, nós dizemos, não são movidos pelo bem geral, como tal, mas pelo desejo por um mundo social em que, como livres e iguais, podem uns cooperar com os outros em termos que todos podem aceitar. Eles insistem que a reciprocidade deve manter dentro desse mundo de modo que cada um obtenha benefícios, juntamente com os outros. Em contraste, as pessoas não são razoáveis no mesmo aspecto básico quando eles planejam se envolver em esquemas de cooperação, mas não estão dispostos a honrar, ou até mesmo a propor, exceto como um pretexto público necessário, quaisquer princípios ou normas gerais para especificar termos justos de cooperação. Eles estão prontos para violar os termos que se adaptem aos seus interesses quando as circunstâncias o permitirem.

${ }^{6}$ Pertinente deixar consignado, por óbvio, a impossibilidade de generalização absoluta. Possível afirmar existirem pessoas que, ao alvedrio dos seus interesses particulares, agem em acordo com os preceitos morais não à toa foram apresentados os dois perfis comprtamentais holmesianos - bem como aquelas pessoas altruístas, que extrapolam, em benefício de outrem, o comportamento médio socialmente desejável.
} 
o good man não oferece risco de insurgência -, poderiam sertraçadas estratégias normativas adequadas à consecução dos fins legislativos almejados ${ }^{7}$ (HOLMES, 2008, p. 269). A partir da perspectiva do bad man, portanto, o Estado passa a se municiar de argumentos práticos que possam conduzir a uma tomada de decisão mais eficaz quando da eleição das estratégias normativas. Pode-se priorizar, à exemplo, a adoção de técnicas de incentivação (tais como benesses fiscais, v.g.) quando o incremento repressório não se revelar suficiente a direcionar o comportamento dos indivíduos. Trata-se, todavia, de tópico que merece ser desenvolvido com maior aprofundamento.

\section{CARÁTER DIRETIVO DO DIREITO}

A sugestão de POSNER (2007, p. 486) no sentido de que o Direito pode ser melhor compreendido a partir perspectiva de maximização das riquezas e busca de benefícios por parte dos indivíduos que compõem o corpo social revela-se imperiosa à análise funcional que se pretende consignar, consoante será demonstrado ao final desta seção. No entanto, para melhor compreensão da real importância da análise comportamental do legislado para o prognóstico de normas tentendes à ineficácia,faz-se necessária uma breve digressão acerca de questões fundamentais que permeiam o Direito, a saber: o que é o Direito?Que mecanismos o Direito dispõe para regular o comportamento humano?

\subsection{Estrutura normativa}

Norberto Bobbio desenvolve o tema com maestria ao apresentar a sua compreensão de uma teoria normativa do direito. Afirma o autor italiano que as regras do direito, as regras sociais, regras morais, regras do costume e preceitos religiosos, possuem, como elemento característico e coincidente, a missão de dirigir a ação dos indivíduos a elas submetidos à adoção de determinado comportamento em detrimento de outro, valendo-se, para tanto, de uma estrutura de proposições normativas (2010, p. 18).

Adotando um ponto de vistaformal (com enfoque para a estrutura da norma, independente do seu conteúdo material), aduz que as normas jurídicas são expressas a partir

\footnotetext{
${ }^{7}$ No que atine a tal desinteresse pela conduta do goodman, cumpre deixar assentada, de plano, posição divergente por parte da autora, cuja justificativa será desenvolvida adiante, no item 4.2.
} 
de proposições de natureza preponderantemente prescritivas, com função de exprimir um comando (são, portanto, imperativos)voltado a influenciar o comportamento alheio, levando o comandado a fazer ou deixar de fazer algo (2010, p. 61-70). Assim, a par das discussões que pairam o questionamento no sentido de se seriam todas as normas jurídicas imperativos (tema cujo detalhamento torna-se inviável no bojo do presente ensaio, em atenção à objetividade), ${ }^{8}$ Bobbiodemonstra filiar-se à teoria imperativista do direito, à luz da qual todas as normas jurídicas estatuem, ainda que implicitamente, comandos.

Cumpre aqui tecer um segundo parêntesis para apresentar a distinção formulada por Immanuel Kant entre imperativos categóricos e imperativos hipotéticos. À luz da doutrina kantiana, categóricos seriam aqueles comandos bastantes em si mesmo, não vinculados a qualquer condição para sua realização ou oferta de alternativa ao comandado. Pode ser considerado imperativo categórico, à exemplo, o mandamento "não matarás". Noutra senda, hipotéticos seriam os comandos voltados a apresentar condições para realização de um resultado, ofertando ao comandado o exercício do livre-arbítrio com vistas à obtenção ou não do resultado. (Ou, nas palavras de Bobbio [2010, p.85], "são aqueles que prescrevem uma ação boa para alcançar um fim, ou seja, uma ação que não é boa em sentido absoluto, mas é boa apenas caso se queira, ou se deva, alcançar certo fim e, portanto, é realizada condicionadamente para a obtenção do fim.”). Para melhor elucidação, um exemplo pode ser obtido a partir da análise do tipo penal homicídio, ao qual é cominada uma pena de reclusão.Se admitido como imperativo hipotético, o comando pode ser assim compreendido: "Se não desejas ver-se compelido a cumprir pena de reclusão, não deves matar alguém".Os imperativos categóricos, segundo Kant (2007, p. 35), seriam característicos da legislação moral, podendo então ser chamados de normas éticas; os imperativos hipotéticos, compreendidos como normas técnicas ou pragmáticas, poderiam ser associados às legislação jurídica.

Tal exposição não se faz sem motivo: partindo-se da compreensão no sentido de que os imperativos hipotéticos podem ser descritos a partir de fórmula "Se... então...", o posicionamento adotado no presente ensaio revela-se no sentido de que as normas jurídicas, em realidade, não exprimem comando categórico, mas apresentam (com o intuito de

\footnotetext{
${ }^{8}$ Para aprofundamento, sugere-se leitura do capítulo IV da sua obra Teoria Geral do Direito, em que as posições principais foram sistematizadas pelo autor.
} 
persuadir, bem verdade), alternativa de ação ao legislado. Podem ser assim traduzidas: "Se não queres, incorrer na sanção $\mathrm{X}$, deves agir de forma $\mathrm{Y}$ ", "Se agires de forma $\mathrm{Y}$, arcará com as consequências X", "Se queres produzir o efeito W, deve realizar Z"; Assim, o argumento ora sustentado coaduna com a afirmação de que o legislado é livre para escolher as suas ações (e assim o faz, em um plano real) sopesando os seus próprios interesses ${ }^{9}$.

Encerrando tal abstração e retornando à análise da doutrina de Bobbio, mister registrar ainda que, vencida a discussão acerca da imperatividade normativa, para ele, o ponto focal da distinção entre as normas jurídicas e as demais espécies normativasreside exclusivamente no modo em que se dá a resposta à violação: através da sanção externa e institucionalizada (2010, p. 142-153). Destaque-se:

Quando se fala de sanção institucionalizada, entendem-se três coisas, ainda que nem sempre elas se encontrem juntas ao mesmo tempo, a saber: 1) para toda violação de uma regra primária, é estabelecida a respectiva sanção; 2) é estabelecida, mesmo que dentro de certos limites, a medida da sanção; 3) são estabelecidas as pessoas encarregadas de obter a sua execução. Como se vê, trata-se de limitações que tendem a disciplinar o fenômeno da sanção espontânea e imediata de grupo. Com a primeira limitação assegura-se a certeza da resposta; com a segunda, a proporcionalidade; com a terceira, a imparcialidade. Todas as três limitações, juntas, têm o objetivo comum de aumentar a eficácias das regras institucionais e, em suma, da instituição no seu todo. Atendo-nos a esses critérios, poderíamos dizer que a característica das normas jurídicas é serem normas, em relação às normas morais e sociais, com eficácia reforçada (2010, p. 153).

Em apertada síntese, o ponto central da distinção entre normas jurídicas e demais espécies normativas é o fato de existir, em relação às primeiras, todo um arcabouço direcionado à apresentação imediata de uma resposta à ação praticada em desacordo com o dever-ser normativo, de forma a garantir a certeza da sanção. Bobbio (2010, p. 193), portanto, ao definir o direito em função da existência de sanção intitucionalizada, conclui

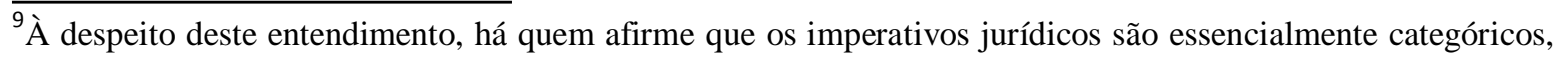
à exemplo de Karl Engisch (2014, p. 52), quando aduz que "constituiria um mal-entendido lastimável pensarse que a regra jurídico-penal poderia significar que nos pertence a escolha entre matar ou não matar, entre a prisão e a liberdade [...]. O direito moderno pró́be o homicídio com tanta firmeza quanto a lei mosaica." Resguardadas as devidas vênias, ousa-se discordar.
} 
que para que o primeiro existafaz-se necessária uma organização, um conjunto de normas sistematicamente organizadas, sob a égide de um instituição apta a aplicar a eventual sanção.

Assentadas tais considerações, é possível retomar ao questionamento formulado no início desta seção para assim responder à indagação sobre o que é, afinal, o Direito. E a conclusão apresentada pode ser subtraída das lições de Soares acerca da natureza das normas jurídicas(2013, p. 41):

As normas jurídicas são normas sociais que correspondem ao chamado mínimo ético, visto que, ao disciplinar a interação social do comportamento humano, estabelecem padrões de conduta e os valores indispensáveis para a sobrevivência de um dado grupo social. $\mathrm{O}$ direito está situado, portanto, na última fronteira do controle social, configurando o núcleo duro das instâncias de normatividade ética, atuando na sanção jurídica quando o sujeito transgressor ingressa na zona mais restrita do juridicamente proibido.

Note-se que, até as presentes linhas, a abordagem da sanção parece conduzir o leitor à idéia de punição exclusivamente. É, portanto, chegado o momento de apresentar a idéia de sanção premial.Para exposição das idéias basilares que permeiam a análise funcional do direito e o papel das sanções premiais, adotar-se-á também a doutrina de Bobbio, valendose, todavia, de momento mais maduro da sua trajetória como autor. ${ }^{10}$

\subsection{A função promocional do Direito.}

Bobbio, na obra Da estrutura à função: novos estudos de teoria do Direito, engendra a tarefa de desmistificar o paradigma estruturalista intimamente relacionado à concepção puramente normativa do Direito (caracteríristica da visão kelseniana), em que o

\footnotetext{
${ }^{10}$ Mario Losano, ao prefaciar a edição brasileira da obra Da estrutura à função: novos estudos de teoria do Direito, cuida de resumir o percurso acadêmico realizado por Bobbio, ressaltando a conexão à análise estrutural positivista de Kelsen, a partir dos anos 1949 até os idos da década de setenta, até o período a partir do qual o autor de Turim passou a aproximar-se de uma concepção sociológica do Direito, em detrimento de uma olhar puramente estrutural, através da qual a função promocional assume papel de maior relevo. Consigna, não obstante, que a atração de Bobbio por uma compreensão funcional do direito não implica na rejeição à visão estrutural de outrora, porquanto sustente a necessidade de integração entre ambos pontos de vista (LOSANO, in BOBBIO, 2007, p. XL).
} 
ordenamento jurídico torna-se responsável por exercer o controle social, ditando as normas e padrões de conduta (portando, o "dever ser") a partir da imposição de mecanismos de repressão e sanção. $\mathrm{O}$ autor assenta a premissa de que na sociedade moderna, a visão do direito enquanto ordenamento puramente coativo não se revela adequada, devendo ceder espaço a uma teoria que, em lugar de compreender o direito como um sistema estruturado em um arcabouço imperativo-coercitivo - partindo-se da premissa que as normas positivadas impõem mandamentos de observância obrigatória, cominando uma sanção para o desacato -há de ser adotada uma concepção do Direito enquanto promovedor e intervencionista, capaz de induzir os legislados a agirem de acordo com o comportamento socialmente desejado (Bobbio, 2008, p. 12).

Bobbio (2008, p. 17) defende que o Estado social encontra no Direito importante instrumento de controle social e, portanto, sustenta a necessidade de efetivação da função promocional do direito, afirmando estar esta indissociavelmente conexa às técnicas de encorajamento -gênero que comporta duas espécies:sanções positivas, sob forma de recompensas, e facilitações, auxílios preparatórios à realização da ação desejada compreendidas como mecanismos incentivatórios que, em oposição às multas, indenizações, reparações, ressarcimentos, v.g, prezam pela promoção de um comportamento positivo e socialmente desejado.Para o autor italiano, as técnicas de encorajamento engendram o papel de motivar ações que possam romper com o modelo conformista da inércia, estimulando a prática de atos concretamente capazes de impactar positivamente no cenário paradigma. Destaque-se:

Podemos imaginar duas situações limite: aquela com que se atribua valor à inércia, isto é, ao fato de as coisas permanecerem como estão, e aquela em que se atribua valor positivo à transformação, isto é, ao fato de a situação subseqüente ser diferente da anterior. No âmbito, pois, das duas situações (de inércia e de transformação), podemos imaginar dois pontos de partida distintos: aquele em que o comportamento seja permitido e aquele em que o comportamento seja obrigatório. No caso de um comportamento positivo, o agente está livre para fazer ou não fazer alguma coisa, ou seja, está livre para valer-se da própria liberdade para conservar ou inovar. Se o ordenamento jurídico julga positivamente o fato de o agente valer-se do mínimo possível de sua liberdade, procurará desencorajá-lo a fazer o que lhe é lícito. Como se vê, a técnica do desencorajamento tem uma função conservadora. Se, 
ao, contrário, o mesmo ordenamento julga positivamente o fato de o agente servir-se o máximo possível de sua liberdade, procurará encorajá-lo a se valer dela para mudar a situação existente: a técnica de encorajamento tem uma função transformadora ou inovadora. (BOBBIO, 2008, p. 19)

Em outras palavras, enquanto o modelo preponderantemente repressivosancionatório tem por missão impedir a prática de comportamentos socialmente não desejados (sejam atos comissivos ou omissivos), ao modelo positivo-incentivatório (leia-se, promocional) interessa a proliferação dos comportamentos socialmente desejados, fazendo com que o legislado adote ações (sejam comissivas ou omissivas) que extrapolem os parâmetros minimamente impostos, realizando um plus, ou seja, um comportamento superconforme (Nicola Pennella [2011, p. 60] sintetiza a definição de um comportamento superconforme como sendo aquele "che supera per eccesso lo standard richiesto dalla norma".)

Pertinente, ainda neste contexto, registrar que Alexandre Altmann (2010, p. 62), efetuando releitura da obra de Bobbio, aduz relevante observação no que atine à diferenciação entre normas positivas/normas negativas e sanções positivas/sanções negativas. Enquanto as primeiras refletem os comandos e proibições, as sanções, seja, positivas ou negativas, representam prêmios e os castigos, respectivamente.

\section{ANÁLISE APLICADA CENÁRIOAMBIENTAL BRASILEIRO.}

Na esteira da análise dos perfis comportamentais holmesianosaliada à compreensão da natureza diretiva do Direito, passa-se a aplicação das idéias retro consignadas à questão da tutela ambiental.

Como visto, o ordenamento jurídico pátrio é heterogêneo no sentido de assumir dupla função orientadora dos comportamentos dos legislados: uma função corretiva, de caráter eminentemente repressivo e sancionatório, direcionada à obtenção de um comportamento absenteísta,e uma função promocional, de natureza preponderantemente bonificadora, preocupada com a consecução de um comportamento positivo do indivíduo a partir da concessão de benesses diversas. Não obstante esta dúplice possibilidade, percebese que no Brasil persiste uma tendência à adoção de políticas e normas de natureza preponderantemente coercitivas, essencialmente punitivas e pensadas em estimular um 
comportamento negativo por parte do cidadão. Tal panorama subsiste nos mais diversos setores da dogmática jurídica, não escapando a seara ambiental de tal cenário.

À exemplo, dois dos mais releventes princípios norteadores da tutela ambiental prezam pela indução (ainda que por via indireta), de comportamentos negativos por parte do cidadão.

Por um lado, o princípio do Poluidor - Pagador almeja, a partir da incorporação ao sistema jurídico da regra econômica de alocação de custos, a internalização das externalidades negativas decorrentes da atividade causadora de degradação ambiental. No que atine ao princípio da responsabilização, consubstanciado no o $\S 3^{\circ}$ do art. 225 da Constituição Federal, que dispõe que "As condutas e atividades consideradas lesivas ao meio ambiente sujeitarão os infratores, pessoas físicas ou jurídicas, a sanções penais e administrativas, independentemente da obrigação de reparar os danos causados" torna-se evidente o seu caráter repressivo-negativo.

\subsection{O típico bad man brasileiro.}

Sucede que o modelo de tutela ambiental amparado nos mandamentos insculpidos nos princípios do poluidor-pagador e da responsabilização não se revelam suficientes a conter os incovenientes do progresso econômico característicos da contemporânea sociedade de capitalista.

Por um lado, é inconteste que a adoção de métodos repressivos demanda a existência de um adequado aparato de fiscalizaçãoe controle por parte do poder público, sob o risco de restarem inócuas as prescrições impositivas criadas, o que, por conseguinte, implica em elevada despesa pública. No Brasil, é notória a carência da Administração nesse sentido (em todas as esferas): a ausência de agentes fiscalizadores, aliada a escassez de recursos destinados a realização das atribuições de polícia administrativa e a extensão territorial do país acabam por inviabilizar a perfeita fiscalização do cumprimento de normas ambientais.

Interessante é o posicionamento de Gordilho (2011, p. 95), nesse sentido, ao abordar a questão do controle das externalidades ambientais negativas por parte do Estado regulador: 
O Estado regulador, ao enfrentar o problema das externalidades ambientais, costuma utilizar-se de instrumentos jurídicos de regulação repressivo ou reativo, tais como padrões, proibições e organizações, voltados para a regulação direta (fixação de deveres, restrições e proibições). A implementação destes instrumentos jurídicos de regulação repressiva, no entanto, enfrenta sérios problemas estruturais em um país como o nosso, marcado por desigualdades regionais e sociais injustificáveis, fato este agravado pela ineficiência dos serviços públicos que, muitas vezes, se prestam apenas a favorecer o fisiologismo de grupos políticos dominantes.

Neste âmbito, obad man sabe que a probabilidade de sofrer uma punição severa é remota. Conjectura além: ainda que a irregularidade praticada venha a ser descoberta de forma que possa vir a ser responsabilizado, é provável que os somatório dos benefícios sucessivamente obtidos através das atividades irregulares sejam mais vantajosos que o prejuízodecorrente da sanção que lhe será cominada. Em se tratando de prática não constitutiva de tipo penal, mas apenas ilícito administrativo, muitas vezes o valor da multa compensa os proveitos obtidos até a condenação, principalmente ao se considerar que do universo de uma série de ilícitos praticados, existe a real possibilidade de apenas alguns poucos serem descobertos pelos órgãos fiscalizadores e, uma vez descobertos, a possibilidade de transacionamento subsiste como prerrogativa (à exemplo, no Estado da Bahia, a Lei $\mathrm{n}^{\mathrm{o}}$ 10.431/2006, diploma que, dentre diversos outros aspectos, cuida de regular as infrações administrativas e cominar respectivas penalidades, faculta ao transgressor a conversão da multa aplicada em prestação de serviços de preservação, melhoria e recuperação da qualidade do meio ambiente, nas condições a serem fixadas em Termo de Compromisso, hipótese em que o transgressor será agraciado com desconto equivalente a $50 \%$ sobre o valor da multa consolidada) ${ }^{11}$. Nesta ponderação de interesses, o meio ambiente costuma restar prejudicado.

\footnotetext{
${ }^{11}$ Art. 182 - A multa poderá ser convertida na prestação de serviços de preservação, melhoria e recuperação da qualidade do meio ambiente, devidamente instruído em Termo de Compromisso a ser firmado com o órgão ambiental competente. $\S 1^{\circ}$ - A autoridade competente aplicará o desconto de $50 \%$ (cinquenta por cento) sobre o valor da multa consolidada.

Em que pese o posicionamento prático do órgão ambiental estadual revelar-se no sentido de que, em realidade, não há que se falar em "desconto", mas (e tão somente) conversão do montante de 50\% sobre o valor da autuação em prestação de serviços, de modo que os demais $50 \%$ devem ser adimplidos em pecúnia, à
} 


\subsection{A conduta do good man de tradição antropocêntrica.}

A opção por um modelo incentivatório revela-se capaz de impactar satisfatoriamente também no comportamento daqueles indivíduos que se aproximam ao estereótipo do good man.

Como visto, o good man possui apego aos valores éticos e morais, de modo que costumam direcionar as suas ações não em razão da existência de lei impositiva e sua respectiva sanção, mas por entender ser assim adequado. Espera-se, portanto, que um good man conduza suas ações de acordo com o que é ética, jurídica e socialmente desejado.Sucede que, em matéria de meio ambiente, os valores preservacionistas não estão solidamente arraigados no consciente social, em especial de uma cultura ocidental de matriz tradicionalmente antropocêntrica, como o Brasil.

Segundo Coimbra e Milaré, a concepção figurada de que o homem posiciona-se no centro do universo, quedando os demais seres vivos em sua órbita, em papel subalterno e instrumental (existindo apenas para servir àquele) decorre das posições racionalistasfilosóficase acontígua compreensão de que a ratio, porquanto atributo exclusivo do homem, constituiria valor diferenciador e determinante da finalidade das coisas(2004, p. 4-6).

Dentre os representantes da doutrina estrangeira, Peter Singeré enfático ao afirmar que a tradição ocidental é marcadamente antropocêntricapor influência da tradição judaicocristã, de matriz hebraica,e da filosofia grega antiga. Segundo o filósofo australiano, de acordo com a tradição ocidental dominante, a natureza é posta como algo a serviço do homem, desprovida de valor intrínseco ${ }^{12}$, detentora apenas de valor instrumental. As plantas e os animais são vistos como ferramentas para a consecução dos interesses dos seres humanos de forma que a proteção dos recursos naturais deve ser realizada apenas como

exegese do dispositivo, não é este o entendimento a priorirevelado ao legislado (a possível interpretação errônea realizada pelo legislado certamente influencia a sua tomada de decisão tendente à infração).

${ }^{12}$ Nas lições do próprio SINGER (2006, p. 290), “uma coisa tem valor intrínseco se for boa ou desejável em si; o contraste se dá com o valor instrumental, que é um valor em forma de meio para a obtenção de algum outro fim ou objetivo." 
forma se salvaguarda dos interresses dos próprios seres humanos, para gozo em momento futuro (ou por seus descendentes). Este papel subserviente do meio ambiente pode ser constatado a partir da leitura de diversos trechos da Bíblia. Destaque-se:

O relato bíblico da criação, no Gênesis, deixa bem clara a concepção hebraica do lugar especial ocupado pelos seres humanos no plano divino:Deus disse: "Façamos o homem à nossa imagem e semelhança, para que tenha domínio sobre os peixes do mar, sobre as aves dos céus, sobre a terra e sobre todos os répteis que rastejam pela terra."Portanto, Deus criou o homem à sua imagem, criou-o à imagem de Deus; criou o homem e a mulher.Abençoando-os, disse-lhes Deus: "Crescei e multiplicai-vos, enchei e dominai a terra. Dominai os peixes do mar, as aves dos céus e todas as coisas vivas que se movem na terra." (SINGER, 2006, p. 281).

Singer (2006, p. 281) relembra ainda que o desvalor dos demais seres vivos que não o homem, para o cristianismo,pode ser constatado a partir do exemplo docélebre dilúvio que acometeu a Terra em castigo aos seres humanos, episódio em que teria salvado-se apenas Noé e alguns poucos representantes de cada espécie. Teria Deus, deliberadamente, afogado quase todos os animais e vegetais, apenas em punição ao mau comportamento dos homens.

Mister ressaltar, neste contexto, que a abordagem que se consigna aqui em relação à presença do meio ambiente na construção dogmático-religiosa não se faz sem motivo. Como é cediço, por muito tempo as doutrinas religiosas se fizeram presentes e imbricadas na formação do indivíduo, seja através do ensino formal, seja a partir do senso comum. $\mathrm{O}$ que se pretende demonstrar é que, em síntese, as influências filosóficas antigas - em especial o cristianismo, no ocidente - exerceram papel histórico na formação do consciente social, de forma que não é absurdo atribuir à tal o papel secundário do meio ambiente na estrutura moral do indivíduo ocidental.

Não suficiente, para uma mais ampla compreensão da discussão acerca da dicotomia antropocentrismo x ecocentrismo, pertinente tomar por empréstimo as críticas lançadas por Van Rensselaer Potter ao célebre princípio do desenvolvimento sustentável. Explica-se. Potter, em seu Global Bioethics: Converting Sustainable Development to Global Survival, alerta para a necessidade de susbstituição da idéia de desenvolvimento sustentável (e suas implicações) pela noção de sobrevivência global aceitável. Segundo o autor norte- 
americano, a expressão desenvolvimento sustentável, porquanto carregue consigo duas idéias nucleares, desenvolvimento e sustentabilidade (a primeira, atrelada à idéia de crescimento, expansão do número de empreendimentos bem sucedidos; a segunda, conexa à idéia de assecuração da existência dos recursos naturais por mais algumas décadas), surge como um termo antropocêntrico voltado à salvaguarda dos interesses econômicos de futuras gerações (1995, p. 188). Trata-se, portanto, de uma acepção preponderantemente quantitativa, em que o que se almeja, em realidade, não é a tutela do valor inerente da natureza, mas sim a garantir que gerações futuras possam também fruir, usar e dispor dos recursos naturais. Por outro lado, à idéia de sobrevivência global aceitável está arraigado um comprometimento ético, uma tomada de consciência acerca da posição do homem no contexto da biosfera e da sua responsabilidade quanto à sobrevivência de todos os seres vivos, inclusive a sua própria sobrevivência ${ }^{13}$. Passa-se a pensar na tutela ambiental, portanto, sob um prisma qualitativo.

Cabe aqui apontar que muitos autores ${ }^{14}$ ecocentristas sustentam a necessidade de alteração de um paradigma antropocêntrico para uma concepção ecocêntrica de sociedade e, nesta jornada, a conscientização seria a estrada principal. Parece, não obstante, um tanto romântico acreditar em uma súbita tomada de consciência universal ${ }^{15}$, como através de um insight coletivo. Seria preciso algo a mais, algo que pudesse conduzir à consecução de

\footnotetext{
${ }^{13}$ Fazendo-se uma conexão com as idéias de Fritjof Capra (2006, p. 25), pode-se afirmar que o ecossistema é visto como uma complexa teia de elementos interligados, onde a função biológica de um depende da função biológica de outros, de forma que a própria sobrevivência do ser humano depende da harmonia ecossistêmica: "A percepção ecológica profunda reconhece a interdependência fundamental de todos os fenômenos, e o fato de que, enquanto indivíduos e sociedades, estamos todos encaixados nos processos cíclicos da natureza (e, em última análise, somos dependentes desses processos) [...] A ecologia profunda reconhece o valor intrínseco de todos os seres vivos e concebe os seres humanos apenas como um fio particular na teia da vida." Trata-se, portanto, de uma visão holística e não hierarquizada do meio ambiente, em que todos os seres vivos merecem igual respeito. Este é, inclusive, o princípio do igualitarismo biosférico proposto por Arne Naess (1973, p. 95),

${ }^{14}$ À exemplo, Arne Naess, Aldo Leopold e o próprio Fritjof Capra.

${ }^{15}$ Principalmente ao se acreditar não serem, antropocentrismo e ecocentrismo, paradigmas no sentido kuhniano de conjunto de verdades, ainda que temporárias, que intentam se impor (KUHN, 2006), mas sim cosmovisões, ou seja, modos particulares de percepção do mundo. Trata-se, todavia, de posicionamento cujo aprofundamento torna-se inviável no âmbito do presente ensaio, em atenção à boa síntese.
} 
resultados concretos e auferíveis a prazo mais exíguo... é justamente nesse sentido que Capra (2006, p. 233) ultrapassa o plano da mera abstração e propõe a adoção estratégias passíveis de interferir positivamente na tensão existente entre o desafio da sustentabilidade e a maneira como as sociedades são estruturadas, do ponto de vista econômico: sua sugestão seria uma reforma ecológica dos impostos capaz de, gradualmente, fomentar a eliminação de tecnologias e padrões de consumo nocivos ao meio ambiente.

Possível inferir, portanto, que a estratégia recomendada por Capra tempor escopo a consecução de um direcionamento comportamental, ainda que de forma mediata,através do manejo de instrumentos econômicos, especialmente através da alocação de tributos àquelas atividades potencialmente nocivas à biosfera. Trata-se de idéia próxima(todavia não tão completa, ao que se propõe no presente). Isto, pois, a alocação tributária, há de ser pensada a par da implementação de mecanismos positivos de incentivação.

Em síntese, retomando-se à análise dos perfis comportamentais holmesianos, é plausível admitir que um típico good man deixará de adotar atitudes preservacionistas quando a lei não impuser algum dever de cuidado específico, não apenas em razão da inexistência de mandamento impositivo, mas por tratar-se de assunto que não lhe inspira profunda obrigação de natureza ética ou moral. Em simples palavras, o good man ocidental, em regra, não foi socialmente condicionado a encarar a tutela ambiental como uma necessidade de matriz ético-principiológica, de forma que não lhe parece um erro a adoção de certas atitudes potencialmente lesivas ao meio ambiente.

Não obstante, este mesmo good man, assim como bad man, também busca a potencialização dos seus interesses pessoais (divergem, no entanto, pois, como visto, o primeiro esbarra em limites impostos pela sua própria consciência, a par dos mandamentos normativos), de forma que, ainda que não haja uma diretriz legal ou moral que o obrigue, certamente optará por adotar uma postura protetiva desde que possa auferir algum benefício.

Diante de tal panorama, há de ser ponderada a necessidade de se fazer uma justaposição deuma matriz incentivatória àquela punitiva, viabilizando mecanismos de direcionamento da conduta dos indivíduos, sejam good ou bad man, a partir da criação de estímulos para a preservação ambiental. Desponta, nesta toada, o novel mandamento do 
protetor-beneficiário como alternativa viável a indução comportamental que se pretende obter.

\section{PROTETOR BENEFICIÁRIO E AS INICIATIVAS DE PAGAMENTO POR SERVIÇOS AMBIENTAIS.}

O princípio do protetor-beneficiário ${ }^{16}$ surge no ordenamento jurídico a partir da constatação de que os dispositivos normativos de controle e coerção não se revelam suficientes à consecução dos fins almejados no que atine à tutela ambiental, tornando-se imperiosa a adoção suplementar de instrumentos econômicos para a concretização da plena salvaguarda ambiental.

O Estado, no exercício de sua atividade interventiva, dispõe de mecanismos de duas ordens: instrumentos normativos e instrumentos econômicos. A plena efetivação das políticas ambientais, muitas vezes, depende da conjugação de ambos.Nesta toada, o princípio do protetor-beneficiário desponta como mandamento balizador da prestação de benefícios àqueles atores sociais que adotem, voluntariamente, práticas protecionistas ao meio ambiente.

Altmann(2008, p. 57) é categórico ao apontar a lógica que permeia o novel mandamento:

A lógica que orienta o conceito de "provedor-recebedor" ganha maior proporção se considerarmos que muitos provedores de serviços ecológicos experimentam perdas econômicas em razão dos custos de oportunidade e manutenção. Isso significa que muitas vezes quem opta por preservar deixa de obter ganhos econômicos, com o uso da terra para lavoura ou pastagens, por exemplo. $\mathrm{O}$ princípio do provedorrecebedor busca equacionar esse desequilíbrio cobrindo, no todo ou em

\footnotetext{
${ }^{16}$ Pertinente ressaltar que, não obstante a maioria dos autores que já discorreram sobre o tema denominem de princípio do protetor - recebedor, a nomenclatura protetor-beneficiário adotada por GORDILHO (2011) parece a mais tecnicamente adequada. Isto pois, a idéia da compensação não precisa, necessariamente, ser materializada a partir de remuneração direta, sendo possível, portanto, estabelecer desonerações, permuta de benefícios, dentre outros.
} 
parte, as perdas econômicas experimentadas pelos provedores de serviços ecológicos.

Por custos de oportunidade, entende-se "o valor perdido por não se optar por atividade econômica considerada lucrativa, em prol da conservação do meio ambiente" (Plaza, p. 1508).

Não sem motivo, Frederico Amado (2014, p.78) afirma ser o princípio do protetorrecebedor "a outra face da moeda do princípio do Poluidor-Pagador" ao advogar que os responsáveis pela preservação ambiental, sejam pessoas físicas ou jurídicas, devem ser premiados através do recebimento de benefícios financeiros diretos ou indiretos, como forma de compensação pela atuação em defesa do meio ambiente em detrimento damáxima exploração econômica do seu bem individualmente considerado, adotando como exemplo a situação do proprietário rural que matem reserva legal em área superior àquela estipulada no art. 12 do novel Código Florestal.

Bechara (2010, p.41), ainda, com bastante propriedade, alcança a conceituação por comparação, apontando as divergências entre os princípios do protetor-recebedor e o poluidor-pagador:

O princípio do protetor-recebedor está bem distante dos princípios do poluidor-pagador e do usuário pagador. Estes dois últimos advogam, muito grosso modo, que o poluidor ou usuários de recursos ambientais "invistam" recursos no meio ambiente, com a finalidade de evitar, reparar ou compensar a degradação ambiental (poluidor-pagador), ou de prestar uma retribuição pelo uso dos bens ambientais (usuáriopagador), enquanto o primeiro pretende que o protetor do meio ambiente "receba" recursos ou outros benefícios, com a finalidade de compensá-lo ou estimulá-lo a sofrer determinados ônus, em nome do bem coletivo.

Aclaradas as distinções necessárias, importante consignar que o princípio do protetor-beneficiário foi expressamente incorporado ao ordenamento jurídico pátrio a partir da edição da Lei $\mathrm{n}^{\circ} 12.305$ em 02 de agosto de 2010, que institui a Política Nacional de Resíduos Sólidos - PNRS,que em seu art. $6^{\circ}$, inciso II, aduziu serem princípios da PNRS o poluidor-pagador e o protetor-recebedor.

A partir de então, foiincorporado em outros diplomas normativos de maneira pontual.No âmbito do estado de Minas Gerais, v.g., foi instituído o programa Bolsa Verde, a partir da edição da Lei Estadual n $n^{\circ}$ 17.727/08, com o objetivo de ofertar premiações 
pecuniárias aos agricultores familiares e pequenos produtores rurais que adotarem ações voltadas à manutenção e a recuperação da cobertura vegetal nativa em seus imóveis;em âmbito federal, pode-se destacar a criação do Programa de Desenvolvimento Sustentável da Produção Familiar Rural da Amazônia - PROAMBIENTE, que viabiliza a remuneração de serviços ambientais como preservação da biodiversidade, eliminação de agroquímicos, redução do desmatamentona região amazônica.

Nada obstante, o princípio do protetor-beneficiário, para a adequada consecução dos fins a que se propõe, deve ultrapassar o plano da generalidade e abstração e ser ampla e sistemicamenteoperacionalizado. Tal operacionalização deverá ocorrer a partir da implementação de mecanismos de incentivação positiva, principalmente a partir da adoção e políticas governamentais e estratégias voltadas à sedimentação de um sistema depagamentos por serviços ambientais.

\subsection{Serviços ambientais $x$ serviços ecossistêmicos.}

À respeito do tema, uma dúvida parece ser contumaz: o que são, afinal, serviços ambientais e quem os presta?

$\mathrm{O}$ termo serviços ambientais, muitas vezes erroneamente confundido com a expressão serviços ecossistêmicos, refere-seàs ações ou atividades humanas que resultem na manutenção, preservação, conservação, restauração, recuperaçãoou melhoria dos ecossistemas e serviços ecossistêmicos que estes fornecem. Por serviços ecossistêmicos, por outro lado, entende-seos benefícios obtidos pelo homem decorrentes das condições e processos gerados pelos ecossistemas naturais, incluindo aqueles gerados pelas espécies e os propiciados por seus genes, que resultam em benefícios tangíveis e intangíveis necessários para a sobrevivência dos sistemas naturais, seu equilíbrio ecológico e para o bem-estar humano. ${ }^{17}$

Para melhor compreensão, os serviços ecossistêmicos podem ser sistematizados e agrupados em quatro categorias:a) serviços de suporte, à exemplo formação do solo, ciclagem de nutrientes, sumidouro de resíduos; b) serviços de provisão, relacionados aos

\footnotetext{
${ }^{17}$ Conceitos extraídos e adaptados do art. $2^{\circ}$, incisos XVII e XIII, da Lei ${ }^{\circ} 13.233$ de 12 de janeiro de 2015, do Estado da Bahia.
} 
produtos derivados dos ecossistemas, à exemplo do fornecimento de madeira, sementes, alimentos, dentre outros; c) serviços de regulação, à exemplo da regulação do clima, seqüestro de carbono pelos vegetais, polinização, dentre outros; d) serviços culturais, relacionados aos benefícios de natureza imaterial proporcionados pela natureza, à exemplo da beleza cênica, valor espiritual, dentre outros.

Os serviços ambientais, enquanto ações realizadas pelo homem, podem ser agrupadas em modalidades correlacionadas às diversas categorias de serviços ecossistêmicos supra destacadas, a exemplo: reflorestamento, proteção e manutenção de florestas nativas, conservação e melhoramento do solo através de técnicas voltadas à contenção e/ou reversão de processos erosivos, gestão de resíduos, incluindo reciclagem e reutilização, dentre diversos outros.

Percebe-se assim, em apertada síntese, que os serviços ecossistêmicos são aqueles benefícios direta ou indiretamente proporcionados pela natureza ao homem e demais espécies. Os serviços ambientais, noutra senda, são ações preservacionistas voluntariamente engendradas pelo homem com o objetivo de proteger (preservar, restaurar ou melhorar) os ecossistemas e, por conseguinte, garantir a perpetuação dos serviços ecossistêmicos.

Assentados tais conceitos fundamentais, a compreensão do que se pretende através da implementação de mecanismos de pagamento por serviços ambientais surge quase intuitivamente. A mais completa definição do que se entende por sistema de pagamentos por serviços ambientais (PSA) parece ser aquela constante da Lei Estadualn ${ }^{\circ} 13.233$ de 12 de janeiro de 2015, do Estado da Bahia, a saber:

Art. $2^{\mathbf{0}}$ - Para os fins previstos nesta Lei, entende-se por:[...] Sistema de Pagamento por Serviços Ambientais: estratégia de preservação dos ecossistemas, na qual o provedor recebe pagamentos ou incentivos condicionados, diretamente do pagador ou através do mediador, como retribuição, monetária ou não, pelos serviços ambientais executados por ele, tais como atividades de manutenção, preservação, restauração, recuperação, uso sustentável ou melhoria dos ecossistemas ou pelos serviços ecossistêmicos que estes provêm isolada ou cumulativamente.

Através da implementação de um sistema de pagamento por serviços ambientais, portanto, busca-se a valorização a partir de premiações conferidas pelo Estado - que podem 
ser de cunho monetário ou não - aos provedores de serviços ambientais, ou seja, àqueles atores que adotem ações positivas voltadas a salvaguarda dos serviços ecossistêmicos.

\subsection{A Lei Estadual $n^{0}$ 13.223/2015 - Política Estadual de Pagamentos por} Serviços Ambientais do Estado da Bahia.

Em 12 de janeiro ogano, após pouco mais de seis meses de tramitação perante a Assembléia Legislativa ${ }^{18}$, fora sancionada a lei estadual epigrafada, editada com o escopo de instituir a Política Estadual de Pagamento por Serviços Ambientais - PSA e o Programa Estadual de Pagamento por Serviços Ambientais - PEPSA, dentre outras providências. Publicada na imprensa oficial no dia imediatamente subsequente à sanção, com vigência imediata, a norma pretende-se aplicável a todas as pessoas físicas ou jurídicas, de direito público ou privado que voluntariamente atuem como provedores, pagadores ou mediadores de serviços ambientais ou ecossistêmicos.

Enquanto Política Estadual, a norma consagra princípios norteadores - destaca-se o princípio do Provedor-Recebedor ${ }^{19}$-, objetivos específicos, diretrizes próprias - dentre as quais merece especial destaque: "oferecer incentivos ou pagamentos condicionados a serem realizados aos provedores dos serviços ambientais" - e instrumentos de efetivação.

Dentre os instrumentos de implementação da Política consignados no artigo $9^{\circ}$, cabe especial destaque aos "incentivos ou pagamentos condicionados, de natureza monetária ou não monetária", a serem destinados aos provedores de serviços ambientais, a saber: pagamentos em dinheiro, incentivos fiscais, selos, certificações, premiações, assistência técnica, bem como fornecimento de atividades de educação ambiental, podendo, inclusive, ser concedidos cumulativamente.

O Programa Estadual de Pagamento por Serviços Ambientais - PEPSA,por sua vez, consoante disposto no art. 15 do diploma legal em comento, enquanto instrumento de operacionalização da Política, consiste em "um sistema público de pagamentos por serviços

\footnotetext{
${ }^{18}$ O Projeto de Lei n ${ }^{\mathrm{o}} 20.863 / 2014$, de iniciativa do Poder Executivo, fora protocolado em 02.06.2014, todavia posteriormente retirado de tramitação, à pedido do Autor, para substituição pelo Projeto de Lei $n^{\circ}$ 21.062/2014, em 30.12.2014, após alterações no texto original.

${ }^{19}$ Nomenclatura adotada pelo legislador, equivalente à utilizada no presente ensaio como "princípio do Protetor-Beneficiário", consoante justificativa consignada em nota anterior.
} 
ambientais, no qual o Estado efetua pagamentos ou concede benefícios condicionados como retribuição monetária ou não, pelos serviços ambientais prestados pelos beneficiários do Programa."Como beneficiários, podem habilitar-se ao recebimento da benesse proprietários e posseiros, ${ }^{20}$ inclusive comunidades tradicionais, que comprovem a execução de serviços ambientais em seus imóveis.

Em apertada síntese, o interessado em habilitar-se ao recebimento do incentivo a ser prestado pelo Estado em reconhecimento à ação preservacionista realizada deve inscreverse no Programa (registre-se, nesta senda, que a adesão é voluntária) e apresentar projeto compatível com as diretrizes da Política (atendendo ao Termo de Referência proposto pelo Conselho Deliberativo do Programa ${ }^{21}$ ), ocasião em que, além da propriedade ou posse do imóvel em que será realizada a ação preservacionista, deverá comprovar a adicionalidade, ou seja, demonstrar que as ações e atividades por ele realizadas fornecem reais e duradouras contribuições sobre os serviços ecossistêmicos e são executadas além das exigências mínimas legais (isto, pois, por óbvio, não há que se falar em concessão de benefício na hipótese em que a conservação ou restauração do meio ambiente é imperativo legal. Só há que se falar no deferimento de benesse, portanto, se restar comprovado que o interessado extrapola positivamente a determinação legal, realizando um plus). Aprovado o projeto, será lavrado instrumento jurídico com vistas à formalização da adesão ao Programa, disciplinando os direitos, obrigações e prazo de vigência.

Há de se consignar a ressalva, no entanto, de que a norma em comento encontra-se pendente de regulamentação e, nesse sentido, muitos questionamentos carecem de resposta(tem-se notícias, no entanto, de que o Poder Executivo engendra esforços com vistas à edição de Decreto Regulamentar em um curto interregno), de forma que ainda não pode ser integralmente operacionalizada. Entretanto, trata-se de precioso avanço e que certamente conduz o Estado da Bahia a uma posição vanguardista no que atine à tentativa de implementação de políticas sistêmicas voltas à tutela ambiental, alinhadas à necessidade

\footnotetext{
${ }^{20}$ Pertinente registrar que o artigo $2^{\mathrm{a}}$, inciso III da norma em comento inclui, dentre o rol dos possíveis beneficiários, "usuários". Trata-se de expressão imprecisa, carecendo de aprimoramento. Restam dúvidas se a norma está a tratar de meros detentores ou cessionários de direito real de uso de bem imóvel público, v.g.

${ }^{21}$ Composto por 15 membros, nos termos do art. 22, assegurada a participação da sociedade civil.
} 
de efetiva adoção de sanções premiais voltadas a fomentar um comportamento positivo por parte do legislado.

\section{CONCLUSÃO}

À guisa de arremate, passa-se a reafirmar as premissas já apresentadas no corpo do presente para, em seguida, possa-se alcançar a conclusão esperada.

De acordo com as lições de Oliver Wendell Holmes,o estereótipo do bad man deve atribuído àquele indivíduo aparenta desapego às regras morais, direcionando sua conduta de modo a evitar as consequiências legais e sanções positivadas, visando apenas a sua própria satisfação. Não somente. Compreendido como uma típica versão do homo economicus, interessado em maximizar os seus benefícios e interesses, é capaz de violar uma prescrição normativa se, ao ponderar os proveitos obtidos a partir da infração e as consequiências que lhe poderão ser cominadas, perceber ser mais vantajoso agir contra legem.

Exemplo concreto de indivíduo que pode ser considerado um bad man é aquele do proprietário rural que, ciente do impeditivo legal (ou da existência de normas condicionantes), suprime deliberadamente vegetação nativa sem a devida autorização do órgão ambiental, seja por entender que a atividade agrícola desenvolvida na área afetada the gerará retorno financeiro capaz de saldar, sem prejuízo do lucro, uma sanção pecuniária que lhe seja eventualmente cominada, seja por entender que em face da precariedade fiscalizatória que assola as diversas órbitas governamentais, o benefício auferido compensa o risco de ser descoberto e punido mais severamente. Como é cediço,em se tratando de prática não constitutiva de tipo penal, mas apenas ilícito administrativo, a situação se agrava porquanto muitas vezes o valor da multa compensa os proveitos obtidos até a condenação, principalmente ao se considerar que do universo de uma série de ilícitos praticados, existe a real possibilidade de apenas alguns poucos serem descobertos pelos órgãos fiscalizadores. Nesta ponderação de interesses, o meio ambiente costuma restar prejudicado.

Adotando-se, agora, como exemplo o mandamento insculpido no artigo 12 da Lei $\mathrm{n}^{\circ}$ 12.651/2012, Novo Código Florestal, no sentido de que o proprietário de imóvel rural deve 
manter área com cobertura de vegetação nativa à título de Reserva Legal, do good man brasileiro, de tradição antropocêntrica, espera-se o cumprimento da norma nos limites mínimos nela consignados, nada mais (salvo se lhe for interessante a manutenção de área superior àquela determinada - afinal, o good man também sopesa seus interesses, tendo por limites, todavia, os mandamentos éticos e jurídicos).

Diante de tal cenário, em se tratando de tutela ambiental, urge reconhecer que as normas repressivas não vêm se mostrando suficientes e eficazes a frear os altos níveis de degradação decorrentes de empreendimentos e atividades antrópicas. Faz-se necessário, destarte, um estudo de alternativas ao modelo repressivo-sancionatório de controle das externalidades ambientais.

Nesta toada, as sanções premiais surgem como possibilidade de estimular comportamentos positivos dos diversos atores sociais, a partir da implementação de mecanismos de compensação por serviços ambientais salvaguardados, mecanismos tais capazes de superar o custo de oportunidade a ser sopesado pelo potencial agente degradador quando da decisão acerca da adoção ou não de comportamento lesivo ao meio ambiente em benefício próprio.

Ademais, mister reiterar que as sanções premiais possuem, via de regra, o escopo de fomentar um comportamento positivo por parte do agente a ser beneficiado, ou seja, estimular a prática de um ato comissivo. Em se tratando de tutela ambiental, plausível afirmar que a simples abstenção não se revela suficiente, de forma que igualmente prestimosa se revela a adoção de atitudes práticas e medidas inovadoras que tenham por objetivo não só a reversão dos danos já ocorridos, mas a manutenção da integridade das áreas e espécies tuteladas.

Insta consignar que, a partir do discurso insculpido no presente ensaio, não se pretende desqualificar as normas de natureza essencialmente impositivo-coercitivas, sequer menoscabar os mandamentos de otimização contidos nos princípios do poluidor-pagador e da responsabilização. Pelo contrário. Busca-se, em sede complementar, solidificar argumentos aptos a justificar a necessidade de incorporação à dogmática ambiental de instrumentos capazes de efetivar função promocional do Direito, nos moldes propostos por Norbeto Bobbio, a partir da criação de mecanismos aptos a tornar economicamente mais interessante ao legisladoa adoção de determinado comportamento preservacionista em 
detrimento de outro não desejado pelo corpo social. É justamente nesta senda que desponta o novel princípio do Protetor-Beneficiário, que objetiva implementar ferramentas de estímulo para a preservação do meio ambiente, seja a partir da concessão de remunerações financeiras diretas, benesses fiscais ou, ainda, favorecimentos de ordem não monetária, à exemplo de cursos de aperfeiçoamento e qualificação técnica para agricultores familiares.

Por fim, impende registrar que não se pretende desqualificar o princípio do Poluidor-Pagador, pelo contrário. Este é reconhecido como um dos mais valiosos princípios de direito ambiental. Busca-se, todavia, estudar outro fundamento que possa se aliar a este no intuito de se alcançar uma efetiva proteção ambiental através da ampla participação dos diversos agentes sociais.

Defende-se, portanto, em apertada síntese, o diagnóstico do comportamento do bad man - e também, ainda que em caráter secundário, dos valores que permeiam o contexto social em que o good man está inserido - como ato necessário à adequada elaboração das estratégias normativas a serem adotadas pelo Estado normatizador.

\section{REFERÊNCIAS}

ALTMANN, Alexandre.Pagamento por serviços ecológicos: uma estratégia para a restauração e preservação da mata ciliar no Brasil? (Dissertação de Mestrado) Universidade Caxias do Sul, 2008. Disponível em:<http://tede.ucs.br/tde_arquivos/2/TDE2009-03-12T153023Z-260/Publico/Dissertacao\%20Alexandre\%20Altmann.pdf.>Acesso em 14 dez. 2014.

AMADO, Frederico Augusto di Trindade. Direito ambiental esquematizado. São Paulo: Método, 2014.

BALKIN, Jack M.; LEVINSON, Sanford.The "Bad Man," the Good, and the SelfReliant.Yale Law School Legal Faculty Scholarship Series.Yale, n.261, 1998.Disponívelem:

$<$ http://digitalcommons.law.yale.edu/cgi/viewcontent.cgi?article=1260\&context=fss_paper s> Acessoem: 08mai. 2015.

BECHARA, Erika. A compensação e a gratificação por serviços ambientais na legislação brasileira.In: GALLI, Alessandra (Org.). Direito Socioambiental. Curitiba: Juruá, 2010.

BOBBIO, Norberto. Da estrutura à função:novos estudos de teoria do Direito.Trad. Daniela Beccccia Versiani. Barueri: Manole, 2007. 
. Teoria Geral do Direito. Trad. Denise Agostinetti. $3^{a}$ Ed. São Paulo: Martins Fontes, 2010.

CANOTILHO, J. J. G.. Estado constitucional ecológico e democracia sustentada. In: FERREIRA, H. S.; LEITE, J. R. M. (org.). Estado de direito ambiental: tendências, aspectos constitucionais e diagnósticos. Rio de Janeiro: Forense Universitária, 2004

CAPRA, Fritjof.A teia da vida: uma nova compreensão científica dos sistemas vivos.Trad. Newton Roberval Eichemberg. São Paulo: Cultrix, 2006.

COIMBRA, José de Ávila Aguiar; MILARÉ, Édis. Antropocentrismo x Ecocentrismo na ciência jurídica. Revista de Direito Ambiental, no 36, ano 9, São Paulo, p. 9-41, outubrodezembro de 2004.

ENGISCH, Karl. Introdução ao pensamento jurídico. $11^{\mathrm{a}}$ ed. Trad.Verlag W. Kohlhammer.Lisboa: Fundação Calouste Gulbenkian, 2014.

GICO JR., IVO. Metodologia e Epistemologia da Análise Econômica do Direito. In: Economic Analysis of Law Review. Brasília, n.1, 2010. Disponível em: <http://portalrevistas.ucb.br/index.php/EALR/article/viewArticle/1460> Acesso em : 02 dez. 2014.

GORDILHO, Heron José de Santana. Direito Ambiental Pós-Moderno. Curitiba: Juruá, 2011.

HARDIN, Garrett. The tragedy of the commons.Science Magazine.Vol. 162, n.3859, 1968. Disponível em: <http://www.sciencemag.org/content/162/3859/1243.full> Acesso em: 20 abr.2015

HOLMES JR., Oliver Wendell. The Path of the Law.Harvard Law Review.Massachusetts, n. 457, 2008.Disponível em: <http://www.constitution.org/lrev/owh/path_law.htm> Acesso em: 22 nov. 2014.

KANT, Immanuel. Introdução ao estudo do direito: doutrina do direito.Trad. Edson Bini. São Paulo: Edipro, 2007

KELSEN, Hans. Teoria Pura do Direito. Trad. João Baptista Machado. 7. ed. São Paulo: Martins Fontes, 2006.

KUHN, Thomas. A estrutura das revoluções científicas. Tradução Beatriz Vianna Boeira e Nelson Boeira. 9 ed - São Paulo, 2006. 
NAESS, Arne. The shallow and the deep, long-range ecology movement.Interdisciplinary Journal of Philosophy,A summary', Inquiry, 16: 1, $95-100$. Disponível em: <http://www.tandfonline.com/doi/abs/10.1080/00201747308601682> Acesso em: 13 mar. 2015.

PENNELLA, Nicola. L'oblazione amministrativa delle sanzioni tributarie non penali. Milão: Wolters Kluwer Italia, 2011.

PLAZA, Charlene Maria Coradini de Avila. O mecanismo de pagamentos por serviços ambientais e a discussão sobre a possivel incidencia do imposto sobre serviços de qualquer natureza - ISSQN.Anais do XIX Encontro Nacional do CONPEDI. Disponível em: <http://www.conpedi.org.br/manaus/arquivos/anais/fortaleza/3104.pdf> Acesso em: 09 mai. 2015.

POSNER, Richard. Problemas de filosofia do direito. Trad Jefferson Luiz Camargo. São Paulo: Martins Fontes, 2007.

POTTER, Van Rensselaer. Global Bioethics: building on the Leopold legacy. East Lansing: Michigan State University Press, 1988.

. POTTER, Lisa. Global Bioethics: converting Sustainable Development to Global Survival.Medicine and Global Survival, vol. 2, no. 3, 1995. Disponível em: <http://www.ippnw.org/pdf/mgs/2-3-potter.pdf.>Acessoem 07 mai. 2015.

RAWLS, John. Political liberalism.Expanded Edition. New York: Columbia University Press, 2005.

SEN, Amartya. A idéia de justiça. Trad. Denise Bottman, Ricardo Doninelli Mendes. São Paulo: Companhia das Letras, 2011.

SINGER, Peter. Ética prática. Trad. Jefferson Luiz Camargo. São Paulo: Martins Fontes, 2006.

SOARES, Ricardo Maurício Freire. Elementos de teoria geral do direito. São Paulo: Saraiva, 2013. 